\title{
Histopathologic survey on lung necropsy specimens of 15 patients who died from COVID-19: A large study from Iran with a high rate of anthracosis
}

\author{
Siavash Kooranifar ${ }^{1}$, Alireza Sadeghipour ${ }^{2}$, Taghi Riahi $^{1 *} \mathbb{D}$, Azadeh Goodarzi $^{3 *} \mathbb{D}$, Sanaz Tabrizi ${ }^{1}$, Navid Davoody $^{1}$ \\ Received: 16 Sep 2020 \\ Published: 17 May 2021
}

Abstract

Background: In the pandemic era of Coronavirus disease 19 (COVID-19), one of the most important issues is the nature of real pathological events that occur during disease course in different parts of the body. There are several ways to know more about COVID-related histopathological events,such as tissue sampling which means biopsy from the tissues of either livepeople or necropsy/autopsy of people who died from COVID-19.

Methods: We conducted an original study for assessing histopathological findings of lung necropsy samples collected from 15 Iranian patients. The continuous variables were presented as mean and standard deviation, and for the qualitative data on histopathological findings, the percentage or qualitative scores $(0$ to +3$)$ were used.

Results: We found similar presentations of COVID-related histopathologic events regarding percentage and severity in pulmonary tissue, includinglymphocytic infiltrations, inflammatory infiltrations of septal and perivascular areas, desquamated type 2 pneumocytes, hyaline membrane changes, fibrin material depositions, abnormal changes of alveolar capillaries, presence of megakaryocytes, PMN infiltrations, septal necrosis, microabscess formation and bacterial colony formation. Also, we found few interesting features which were not completely compatible with previous similar studies or newly reported by ours asa high percentage of anthracosis $(86 \%$ : 13 patients) that was not clearly reported in other previous studies, also a lower percentage of microthrombotic vascular lung injuries (20\%: 3 patients), and a higher percentage of viral cytopathic effects (27\%: 4 patients).

Conclusion: This article suggests a greater need for evaluatingthe autopsy samples of COVID-19 patients to provide better management strategies and propose the question of whether anthracosismay be a mortality risk factor in COVID-19 patients.

Keywords: COVID-19, Autopsy, Necropsy, Biopsy, Tissue Sampling, Histopathology, Lung, Anthracosis

Conflicts of Interest: None declared

Funding:None

*This work has been published underCC BY-NC-SA 1.0 license.

Copyright $\odot$ Iran University of Medical Sciences

Cite this article as: Kooranifar S, Sadeghipour A, Riahi T, Goodarzi A, Tabrizi S, Davoody N. Histopathologic survey on lung necropsy specimens of 15 patients who died from COVID-19: A large study from Iran with a high rate of anthracosis.Med J Islam Repub Iran. 2021 (17 May);35:63. https://doi.org/10.47176/mjiri.35.63

\section{Introduction}

In the pandemic era of COVID-19, one of the most im-

Corresponding author: Dr Taghi Riahi, riahi.t@iums.ac.ir Dr Azadeh Goodarzi, goodarzi.a@iums.ac.ir

1. Department of Internal Medicine, School of Medicine, Rasool Akram Medical Complex, Iran University of Medical Sciences, Tehran, Iran

2. Department of Pathology and Oncopathology Research Center, Rasool Akram Medical Complex, Iran University of Medical Sciences, Tehran, Iran

3. Department of Dermatology, Rasool Akram Medical Complex, Iran University of Medical Sciences, Tehran, Iran portant issues is the nature of real pathological events that

\section{$\uparrow$ What is "already known" in this topic:}

A critical point for better management of COVID-19 is: knowing more about exact pathomechanisms of events in different organs during disease course and COVID-related histopathological events like tissue sampling, either biopsy or necropsy/autopsy of died people, collecting from different populations.

\section{$\rightarrow$ What this article adds:}

In lung necropsy of 15 Iranian patients, we found similar presentation of histopathologic events compared with previous similar studiers: A high percentage of anthracosis and viral cytopathic effects, and a lower percentage of microthrombotic vascular lung injuries, suggesting some probable differences in pathologic events among different populations. 
occur during disease course in different parts of the body.

There are many articles about necropsies (core needle biopsies) and autopsies of different internal organs of patients with COVID-19, especially lung, cardiac and liver $(1-7)$.

In the lung, cytopathic effects - usually with no obvious intranuclear or intracytoplasmic viral inclusions- could be identified as multinucleated syncytial cells with atypically enlarged pneumocytes characterized by large nuclei, amphophilic granular cytoplasm and prominent nucleoli in intra-alveolar spaces. Fibrotic pathogenic events especially in the lung, proteinaceous exudates as large protein globules, vascular congestion accompanied by the inflammatory clusters of fibrinoid materials, multinucleated giant cells; pneumocyte hyperplasia and bilateral diffuse alveolar damage (DAD) with cellular fibromyxoid exudates are other histopathologic events. Desquamated pneumocytes and hyaline membrane formation- suggesting interstitial mononuclear inflammatory infiltrates- also have been reported in ARDS dominated by lymphocytes $(1,2)$. The main histopathologic findings of the lung are diffuse alveolar damage (DAD) including injury to the alveolar epithelial cells, hyaline membrane formation and pneumocytes type II proliferation. Fibrotic degeneration consists of the fibroblastic proliferation ofthe extracellular matrix, and fibrin cluster formation. In the case of high intra-alveolar neutrophilic infiltrations, bacterial superinfection could be considered. Changes in the liver and heart are likely secondary or related to the underlying diseases or drug dependent (especially about the liver). The liver may exhibit mild lobular infiltration by small lymphocytes, and centrilobular sinusoidal dilation along with patchy necrosis; and the heart may showmild focal fibrosis and mild myocardial hypertrophy (3).

$\mathrm{DAD}$, including hyaline membrane formation, could be seen in all patients, even non-intubated ones; it is similar to histopathogic features of coronavirus as the severe acute respiratory syndrome (SARS).In the heart, individual cell necrosis, without lymphocytic myocarditis, is the most characteristic finding. Secondary pulmonary infection by microorganisms is of great concern nowadays. The central nervous system did not show any involvement. In recent studies, it had been shown that the most important findings in pulmonary tissue arethe small vessel and capillary thrombosis and microangiopathy with associated haemorrhage that may be the main cause of death. Severe endothelial injury, associated with the presence of intracellular virus, disrupted cell membranes, and widespread thrombosis with microangiopathy, could be characteristic features of lung involvement in COVID-19; so that alveolar capillary microthrombi could be nonetimes more prevalent than patients with influenza and new vessel growth (intussusceptive angiogenesis) could be 2.7 times more than patients with influenza (4-6).

A pathological survey in 23 cases of autopsy from United States (7) showed that SARS-COV-2 infection should be considered a systemic viral infection thatpredominantly involves the lung and heart; in the lung, it presentsas an acute interstitial pneumonia with prominent diffuse alveolar damage (DAD), intra- and extravascular fibrin deposi- tions, interavascularneurophilic entrapments, and microvascularthromotic events. About $20 \%$ of the patients may show major pulmonary thromboemboliand also infarcts and/or hemorrhage as a consequence. In non-hemorrhagic areas, interstitial lymphocytic pneumonitis with intraalveolar fibrin deposits with no hyaline membranes could be seen that is a clue for transition to an acute fibrinous and organizing pneumonia. Multifocal cardiac injuries as acute lymphocytic myocarditis or lymphocytic pericarditis or multifocal acute injury of cardiomyocytes without any inflammatory cellular infiltration, all could be seen. In other vital organs, the depletion of splenic white pulp, focal hepatocellular degeneration and rarely glomerular capillary thrombosis may be the associated features. Moreover, evidence of chronic heart involvement as hypertensive left ventricular hypertrophy, dilated cardiomyopathy, and hypertrophic cardiomyopathy were found in some cases that all were observed as well. Autopsy findings support the direct viral-induced injury of multiple organs like the heart and lungs in the setting of indirect viral-host interactions, which result in procoagulant state and coagulopathic events and pro-inflammatory-cytokine storms. Increased risk for pulmonary thrombotic microangiopathy in addition to the development of deep vein thromboses and major pulmonary thromboembolism could be a fatal picture of new corona virus necessitates early work up for detection and management of coagulopathy in the disease course and use of prophylactic anticoagulants while hospitalization that could be vital when accompanied by the other supportive and therapeutic cares regarding better oxygenation and perfusion.

Considering the different manifestation of the predominance of COVID-19 and its presentation to somehow different over time and in different societies, and apparently multifaceted nature of this global disorder, reliable information of medical records of different societies and geographic locations, including postmortem histopathological findings seems to bevery valuable. Analysis of these original data in the futuremay help to obtain more practical approaches towardthepatients, especially in the case of genetic differences affecting the final outcomes ofCOVID-19. In this original study,we described histopathological findings of necropsy obtained from 15 Iranian patients died from COVID-19.

\section{Methods}

In this original large case series, patients with a diagnosis of COVID-19 hospitalized in April and May 2020 in RasoolAkramMedical Complexaffiliated to Iran University of Medical Sciences who died during disease course were included. In less than 12 hours after their death, patients underwenttransthoracic core needle necropsy in accordance with the complete health protocols that was performed from the fifth intervertebral midclavicular space, anterior axillary and the second midclavicular intercostal space by $16 \mathrm{G}$ biopsy needles. The sample was immediately placed in a media containing $8 \mathrm{cc}$ of $4 \%$ formaldehyde solution and the patient specification label was affixed to the container. Then,the sample transferred to the histopathology laboratory under completely hygienic con- 
ditions. In the laboratory, the samples were placed inside a safety container. Outside layer of the samples' container was disinfected with $70 \%$ ethanol solution. After 48 hours, the samples were routinely prepared for histopathologic survey. Formaline-fixed samples were placed into paraffin blocks and prepared in 3-micron histological sections at 6 levels, stained with hematoxylin and eosin, and examined histopathologically. The continuous variables were presented as mean and standard deviation and for the qualitative data on histopathological findings the percentage or qualitative scores $(0$ to +3$)$, were used. The SPSS Statistics version 22 was used and $p$ value $<0.05$ was considered as statistically significant.

\section{Results}

This study was conducted based on the data available from 15 hospitalized COVID-19 patients who were administered in April and May 2020 and died due to the disease complications. Median age of the patients was 80 (IQR 75.0-90.0) years old (55-93) and they were predominantly male (73.3\% (11 patients) male and $26.7 \%$ (4 pa- tients) female). The mean age of patients was $80.33 \pm 11.60$ years. The mean $\mathrm{SPO}_{2}$ at the time of admission was $77.40 \pm 28.85 \%$. The average lengthofhospitalization before death was about 2-3 weeks. Preliminary examinations showed that $80 \%$ (12) of the patients had evident sign and symptoms of the disease including fever, cough, shortness of breath (Dyspnea) and weakness and 20\% (3) only expressed cough and fever. Further examinations revealed that $80 \%$ of the cases suffered from comorbidities such as senile brain atrophy (6) (based on results of brain CT scan), HTN (3), BPH+CVA+HTN+CABG (2), and DM (2). All patients showed lung involvement based on chest CT Scans. These results indicated that the majority of lesions were bilateral and peripheral; patchy lesions were primarily detected in lower sections or pleural areas;meanwhile, the nodular lesions were primarily detected in bronchovascular bundles. As mentioned, bilateral and peripheral involvement was the most predominant radiologic finding in CT scan images (86.7\%: 13 patients).

The patient's histopathological features are presented in Table 1, and microscopic images of some histopathological findings were demonstrated in Figures 1-5.

\begin{tabular}{|c|c|c|c|}
\hline Characteristics & & Frequency & Percent \\
\hline \multirow[t]{3}{*}{ Lymphocytic infiltration } & Less than $25 \%(+1)$ in necropsy samples & 6 & 40.0 \\
\hline & $25 \%-50 \%(+2)$ in necropsy samples & 8 & 53.3 \\
\hline & More than $50 \%(+3)$ in necropsy samples & 1 & 6.7 \\
\hline \multirow[t]{2}{*}{ Location of Infiltrate } & Alveolar septa & 6 & 40.0 \\
\hline & Alveolar septa+perivascular & 9 & 60.0 \\
\hline \multirow[t]{2}{*}{ Microthrombi } & Absent & 12 & 80.0 \\
\hline & Present & 3 & 20.0 \\
\hline \multirow[t]{3}{*}{ Anthracosis } & Absent in necropsy samples & 2 & 13.3 \\
\hline & Less than $25 \%(+1)$ in necropsy samples & 10 & 66.7 \\
\hline & $25 \%-50 \%(+2)$ in necropsy samples & 3 & 20.0 \\
\hline \multirow[t]{4}{*}{ Desquamated type 2 pneumocytes } & Absent in necropsy samples & 4 & 26.7 \\
\hline & Less than $25 \%(+1)$ in necropsy samples & 6 & 40.0 \\
\hline & $25 \%-50 \%(+2)$ in necropsy samples & 3 & 20.0 \\
\hline & More than $50 \%(+3)$ in necropsy samples & 2 & 13.3 \\
\hline \multirow[t]{2}{*}{ Viral inclusion cytopathic effects } & Absent & 11 & 73.3 \\
\hline & Present & 4 & 26.7 \\
\hline \multirow{4}{*}{ Hyaline membrane changes } & Absent in necropsy samples & 3 & 20.0 \\
\hline & Less than $25 \%(+1)$ in necropsy samples & 6 & 40.0 \\
\hline & $25 \%-50 \%(+2)$ in necropsy samples & 4 & 26.7 \\
\hline & More than $50 \%(+3)$ in necropsy samples & 2 & 13.3 \\
\hline \multirow[t]{3}{*}{ Fibrindeposition } & Absent in necropsy samples & 4 & 26.7 \\
\hline & Less than $25 \%(+1)$ in necropsy samples & 8 & 53.3 \\
\hline & $25 \%-50 \%(+2)$ in necropsy samples & 3 & 20.0 \\
\hline \multirow[t]{5}{*}{ Alveolar Capillaries } & Inflammation, edema & 2 & 13.3 \\
\hline & Inflammation, edema and thrombosis & 1 & 6.7 \\
\hline & Surrounded with edema & 10 & 66.6 \\
\hline & surrounded with edema \&PMN infiltration & 1 & 6.7 \\
\hline & surrounded with edema+fibrous thickening & 1 & 6.7 \\
\hline \multirow[t]{3}{*}{ Megakaryocytes } & Absent & 5 & 33.3 \\
\hline & less than 3 in whole slide & 7 & 46.7 \\
\hline & $\geq 3$ in whole slide & 3 & 20.0 \\
\hline \multirow[t]{3}{*}{ PMN in wall } & Mild or focal & 12 & 80.0 \\
\hline & Moderate & 2 & 13.3 \\
\hline & Severe & 1 & 6.7 \\
\hline \multirow[t]{3}{*}{ Septal necrosis } & Absent & 12 & 80.0 \\
\hline & Extensive & 1 & 6.7 \\
\hline & Focal & 2 & 13.3 \\
\hline \multirow[t]{3}{*}{ Microabscess } & Absent & 13 & 86.7 \\
\hline & Extensive & 1 & 6.7 \\
\hline & Focal & 1 & 6.7 \\
\hline \multirow[t]{2}{*}{ Bacterialcolonies } & Negative & 14 & 93.3 \\
\hline & Present & 1 & 6.7 \\
\hline
\end{tabular}




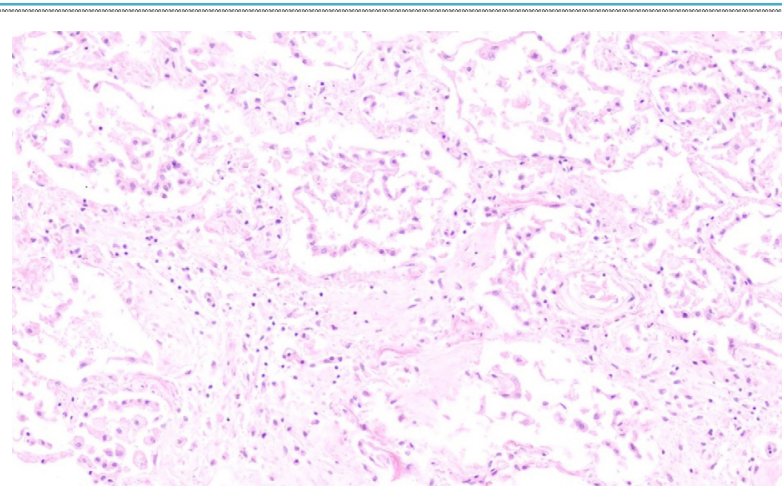

Fig. 1. Septaloedema, inflammation and diffuse hyperplasia of type II pneumocytes (H\&E, X 100)

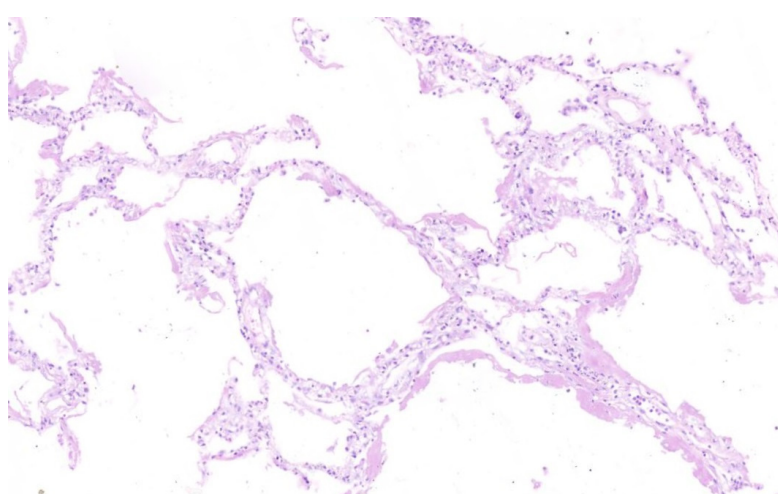

Fig. 2. Hyaline membranes on the surface of alveolar spaces (H\&E, $\mathrm{X} 100)$

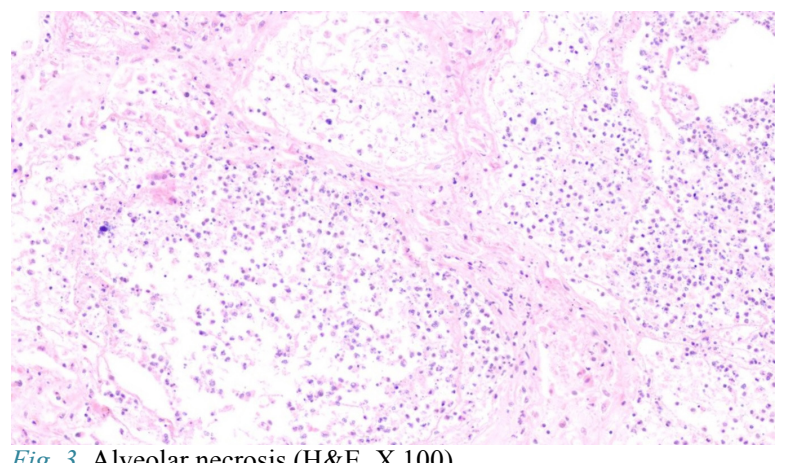

Fig. 3. Alveolar necrosis (H\&E, X 100)

In the Supplementary file (Tables 2-6) that are attached to the main document, we demonstrated demographic characteristics of the patients and the disease also the laboratory, paraclinical and radiographic data of all patients. In the mentionedtables,rows 1 to 15 refer to a specific patient from number 1 to 15 .

In lung necropsies of 15 Iranian patients, we found that all samples had lymphocytic infiltrations that in $60 \%$ of the cases were moderate to severe. Sixty percent of the patients showed inflammatory infiltrations in both alveolar septa and perivascular areas. Eighty percent of our samples did not show any evidence of angiopathties or microthrombotic events. Eighty six percent of the samples showed some degrees of anthracosis. About $73 \%$ (11) of the samples showed desquamated type 2 pneumocytes that in 33\% (5) of the cases were moderate to severe. Viral cytopathic effects were only evident in $27 \%$ (4) of the samples. Hyaline membrane changes

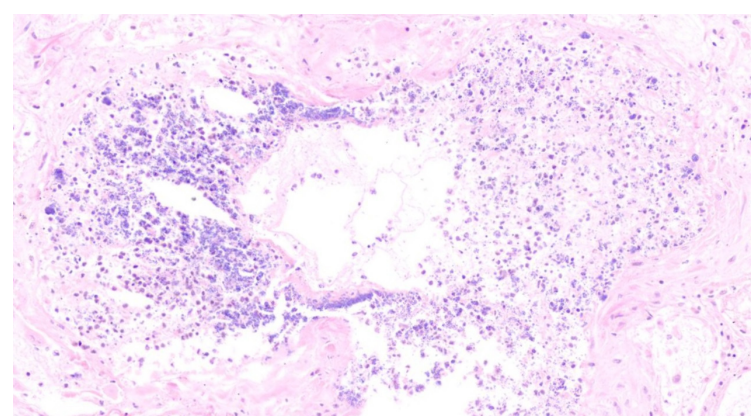

Fig. 4. Alveolar necrosis with bacterial colonisation(H\&E, X 100)

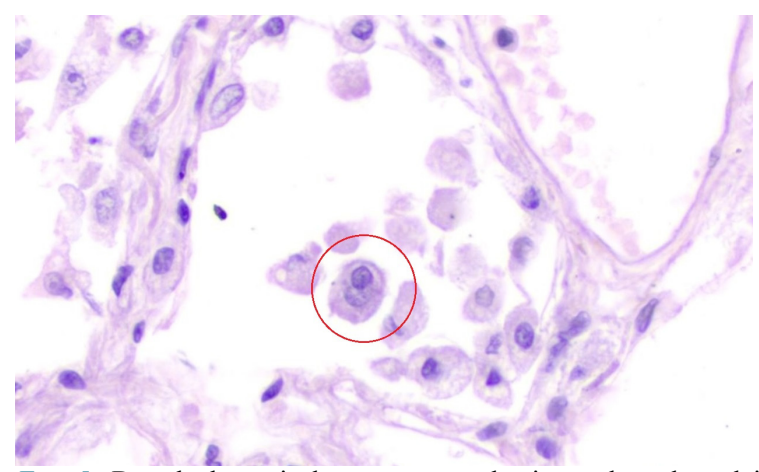

Fig. 5. Detached atypical pneumocyte, having enlarged nuclei with intranuclear inclusion (H\&E, X 400)

were found in $80 \%$ (12) of the cases; in $50 \%$ of cases (6), it wasmoderate to severe. About $73 \%$ (11) of the samples were found to have mild to moderate fibrin material depositions. In 70\% (10) of the cases,alveolar capillaries were surrounded by edema, and megakaryocytes were present in 70\% (10) of the samples as well. Mild or focal PMN infiltrations were evident in the wall of $80 \%$ of the cases. Septal necrosis, microabscess and bacterial colonies were evident in only $20 \%(3), 13 \%$ (2) and $7 \%$ (1) of the cases, respectively. The number and percents have been shown by detail in Table 1 .

\section{Discussion}

Corona viruses are major pathogens of the respiratory system, causing different diseases, and now the novel corona viruse (COVID-19) is one of the biggest catastrophic event of the centuray and global-pandemic with a high mortality rate, approximately $20 \%$ in some studies, and is 30-60 times more fatal than the common annual Influenza.However, there are still lots of unkown aspectes of this fatal infection especially about patients who have been died by COVID-19(8-12).

Based on autopsies, it could be say that COVID-19 is a systemic disease with major pulmonary and cardiovascular involvements in a setting of cytokine storm and inflammatory hypercoagulative state which could also cause susceptibility to microangiopathy and micro/macro thrombotic events (7). The lung primarily could be involved by virus itself and other internal organs even skin could be involved secondary to virus-host interactions which results in severe inflammatory storms.

In the pandemic area, assessing original data of the patients from different population with different genetic characteristics and geographic areas with various envi- 
ronmental factors which may affect disease presentations and courses is of great value for better approach to the patients in a wide spectrum of important issues such as preventive, diagnostic, prognostic and therapeutic fields. In this regards, data of died COVID patients is of great concern to be evaluated, which we have done it in this study on Iranian patients, so far.

There are several ways to know more about COVIDrelated histopathological events such as tissue sampling; it means either biopsy from the tissues of affected livepeople or necropsy/autopsy from people died from COVID19. For better approach to COVID-19, (like many other unknown or lesser-known diseases), a better knowledge about underlying pathophysiologic events is really needed and valuable which also helps to choose more proper and targeted therapies. In this regard, necropsy and autopsy of internal organs and the subsequent histopathological surveys are practical diagnostic approaches, considering the ethical and legal rules (13-15).

Based on previous studies, bilateral diffuse alveolar damage (DAD), proteinaceous exude, pneumocyte hyperplasia, hyaline membrane formation, syncytial giant cells formation, interstitial fibrosis, vascular lumen stenosis, microthrombosis formation, alveolar cavity congestion, desquamation and squamous metaplasia in alveolar epithelial cells and inclusion viral bodies are the histopathologial events in the lung of the patients, who were died from COVID that we have listed from the highest to lowest frequency, respectively (1-7).

The result of our study wasto a large extent compatible with the results of other previous similar studies, but there were some surprising findingsincluding: a high percentage of anthracosis $(86 \%)$ in the deadpatients that was not clearly reported in other previous studies; and also,a lower percentage of microthromboticvascularlung injuries $(20 \%)$ and a higher percentage of viral cytopathic effects $(27 \%)$ compared with other similar studies. Other features such as percentage and severity of lymphocytic infiltrations, inflammatory infiltrations of septal and perivascular areas, desquamated type 2 pneumocytes, hyaline membrane changes, fibrin material depositions, abnormal changes of alveolar capillaries, presence of megakaryocytes, PMN infiltrations, septal necrosis, microabscessformation, and bacterial colony formation, were reported similar to other previous studies.

The term anthracosis means black pigmentation of mucosal and submucosal area of the tracheobronchial tree, also pulmonary parenchyma, or being induced by deposition of carbon, silica, or quartz in macrophages that results in black pigmentation. In many countries, chronic airway diseases are correlated with indoor pollutions, but the most cases of anthracofibrosis have been found in Iran and Korea which was compatible with our findings too;so, considering the prevalence of anthrax in necropsy samples of this study, anthracosis could be proposed as a risk factor of mortality in patients with COVID and its structural, and functional effects on cellular immunity and parenchymal defense mechanisms may be proposed and needed to further studied $(16,17)$.

In patients without anthracosis, the main pattern of chest
CT scan was ground glass opacities and atelectasis; also in patients with the highest degree of anthracosis, we found more emphysema and hyperinflation in CT scans. Since we had no control group and had only 15 patients, we do not know that these findings could be incidental or statistically significant with a higher sample size. All patients with viral cytopathic effects in pulmonary tissue showed ground glass opacities in the chest CT scans. Disseminated centriacinar emphysema and ground glass opacities were found in the chest CT of the patients who had microthrombi in lung necropsy.

Overally, regarding the histopathogic findings in the patients with the highest degree of anthracosis, it should be noted that HTN was among the most prevalent past medical histories, and the average days of hospitalization was lower (about 6-7 days) than the average days of hospitalization of all patients (about 2-3 weeks). Lymphocytic infiltrations was mild and predominantly in septal and perivascular areas; desquamated type 2 pneumocytes and hyaline membrane changes were $<25 \%$, fibrin material depositions;abnormal changes of alveolar capillaries like surrounded edema and presence of megakaryocytesand, and PMN infiltrations were mild, and septal necrosis, microabscess formation, bacterial colony and any cytopathic effects did not observed. Microthrombi were observed in about $30 \%$ of the cases. It may be interpreted a lower hospitalization days before occurrence of death and little higher rates of microthrombi and lower cytopathic effects of necropsy samples in patients with a higher degree of anthracosis that needs more evaluation in future studies and to compare with other studies especially articles of similar geographic area (18).

As we know, COVID-19 is a fatal systemic disease with major pulmonary involvementsand a lot of unknown aspects especially about patients who have been died by virus, which needs more investigations in different populations (8-12). The authors of this study have also focused on multi-potential drugs and specific manifestation of COVID in patients with specific disorders and comorbidities (19-29). After great investigation, we know that many real findings about COVID-19 may be found by more exact focus on all probable pathomechanisms of this disorder especially by studies in the field of autopsy ornecropsy.

\section{Conclusion}

Based on findings obtained from our samples, we found similar presentation of histopathologic events regarding percentage and severity including: lymphocytic infiltrations, inflammatory infiltrations of septal and perivascular areas, desquamated type 2 pneumocytes, hyaline membrane changes, fibrin material depositions, abnormal changes of alveolar capillaries, presence of megakaryocytes, PMN infiltrations, septal necrosis, microabscess formation and bacterial colony formation. Moreover, we found few interesting features which were not completely compatible with previous similar studies or newly reported by ours as:a high percentage of anthracosis $(86 \%)$ that was not clearly reported in other previous studies,also a lower percentage of microthrombotic vascular lung inju- 
ries $(20 \%)$, and a higher percentage of viral cytopathic effects $(27 \%)$.It seems that anthracosis could be proposed as a risk factor for mortality in COVID patients especially in Iranian population. These findings suggest more need to evaluate autopsy samples of patients with COVID-19 for better understanding of pathological events which result in death; comparing the results of different populations of different ethnics and geographic areas for better management strategies in different patients with various genetic predispositions may affect our preventive or therapeutic approaches.

\section{Study limitations}

Since we did not have a concurrent control group and had only 15 necropsy samples, straight forward recommendations about some expected and incidental histopathologic findings is not possible but we hypothesized some comments based on findings of this study.

\section{Acknowledgement}

The authors would like to thank Rasool Akram Medical Complex Clinical Research Development Center (RCRDC) for its technical and editorial assists.

\section{Conflict of Interests}

The authors declare that they have no competing interests.

\section{References}

1. Xu Z, Shi L, Wang Y, Zhang J, Huang L, Zhang C, et al. Pathological findings of COVID-19 associated with acute respiratory distress syndrome. Lancet Respirat Med. 2020.

2. Cascella M, Rajnik M, Cuomo A, Dulebohn SC, Di Napoli R. Features, Evaluation and Treatment Coronavirus (COVID-19). StatPearls. Treasure Island (FL): StatPearls Publishing StatPearls Publishing LLC.; 2020.

3. Tian S, Xiong Y, Liu H,Niu L, Guo j, Liao M, Xiao SY. Pathological study of the 2019 novel coronavirus disease (COVID19) through postmortem core biopsies. Modern Pathol. 2020

4. Fox SE, Akmatbekov A, Harbert JL, Li G, Brown JQ, Vander Heide RS. Pulmonary and cardiac pathology in African American patients with COVID-19: an autopsy series from New Orleans. Lancet Respir Med. 2020.

5. Ackermann M, Verleden SE, Kuehnel M, Haverich A, Welte T, Laenger F, et al. Pulmonary Vascular Endothelialitis, Thrombosis, and Angiogenesis in Covid-19. N Engl J Med. 2020 May 21.

6. Schaller T, Hirschbühl K, Burkhardt K, Braun G, Trepel M , Markl $\mathrm{B}$, et al. Postmortem Examination of PatientsWith COVID-19. JAMA. 2020.

7. Buja LM, Wolf DA, Zhao B, Akkanti B, McDonald M, Lelenwa $\mathrm{L}$, et al. The emerging spectrum of cardiopulmonary pathology of the coronavirus disease 2019 (COVID-19): Report of 3 autopsies from Houston, Texas, and review of autopsy findings from other United States cities. Cardiovasc Pathol. 2020;48:107233.

8. Cascella M, Rajnik M, Cuomo A, Dulebohn SC, Di Napoli R. Features, Evaluation and Treatment Coronavirus (COVID-19). StatPearls. Treasure Island (FL): StatPearls Publishing StatPearls Publishing LLC, 2020.

9. Cennimo DJ, Bronze MS. Coronavirus Disease 2019 (COVID-19). Medscape Updated, 2020

10.Baud D, Qi X, Nielsen-Saines K,Musso D, Pomar L,Favre G. Real estimates of mortality following COVID-19 infection. Lancet Infect Dis. 2020;20:773.

11.Zhou F, Yu T, Du R, Fan G, Liu Y, Liu Z, et al. Clinical course and risk factors for mortality of adult inpatients with COVID-19 in Wuhan, China: a retrospective cohort study. Lancet. 2020

12.Wu C, Chen X, Cai Y, Zhou X, Xu S, Huang H, et al., Risk Factors Associated With Acute Respiratory Distress Syndrome and Death in 
Supplementry files

Table 2.Demographic data of patients and some disease characteristic when admitted to hospital

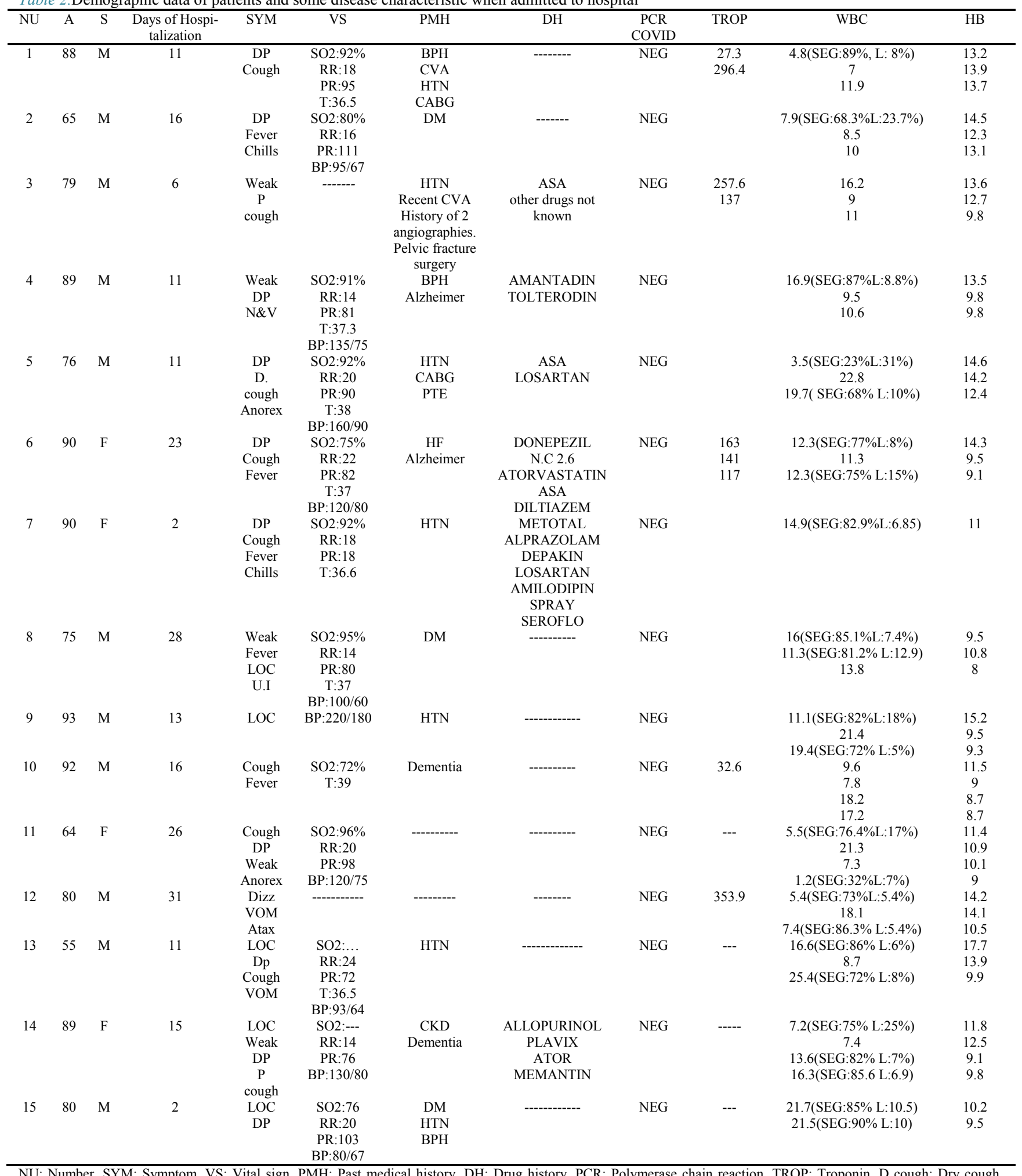

NU: Number, SYM: Symptom, VS: Vital sign, PMH: Past medical history, DH: Drug history, PCR: Polymerase chain reaction, TROP: Troponin, D cough: Dry cough, Pcough: Productive cough, BPH: Benign prostatic hyperplasia, NEG: Negative, L: Lymphocyte, SEG: Segment, N\&V: Nausea and Vomiting, WEAK: Weakness, UI: Urinary incontinence, LOC: Loss of consciousness, WEAK +: weakly positive, PTE: Pulmonary thromboembolism, DP: Dyspnea, Dizz: Dizziness, Atax: Ataxia, VOM:Vvomiting, A: Age, S: Sex, Anorex: Anorexia. 
Histopathologic evaluation of lung necropsies of 15 Iranian COVID patients

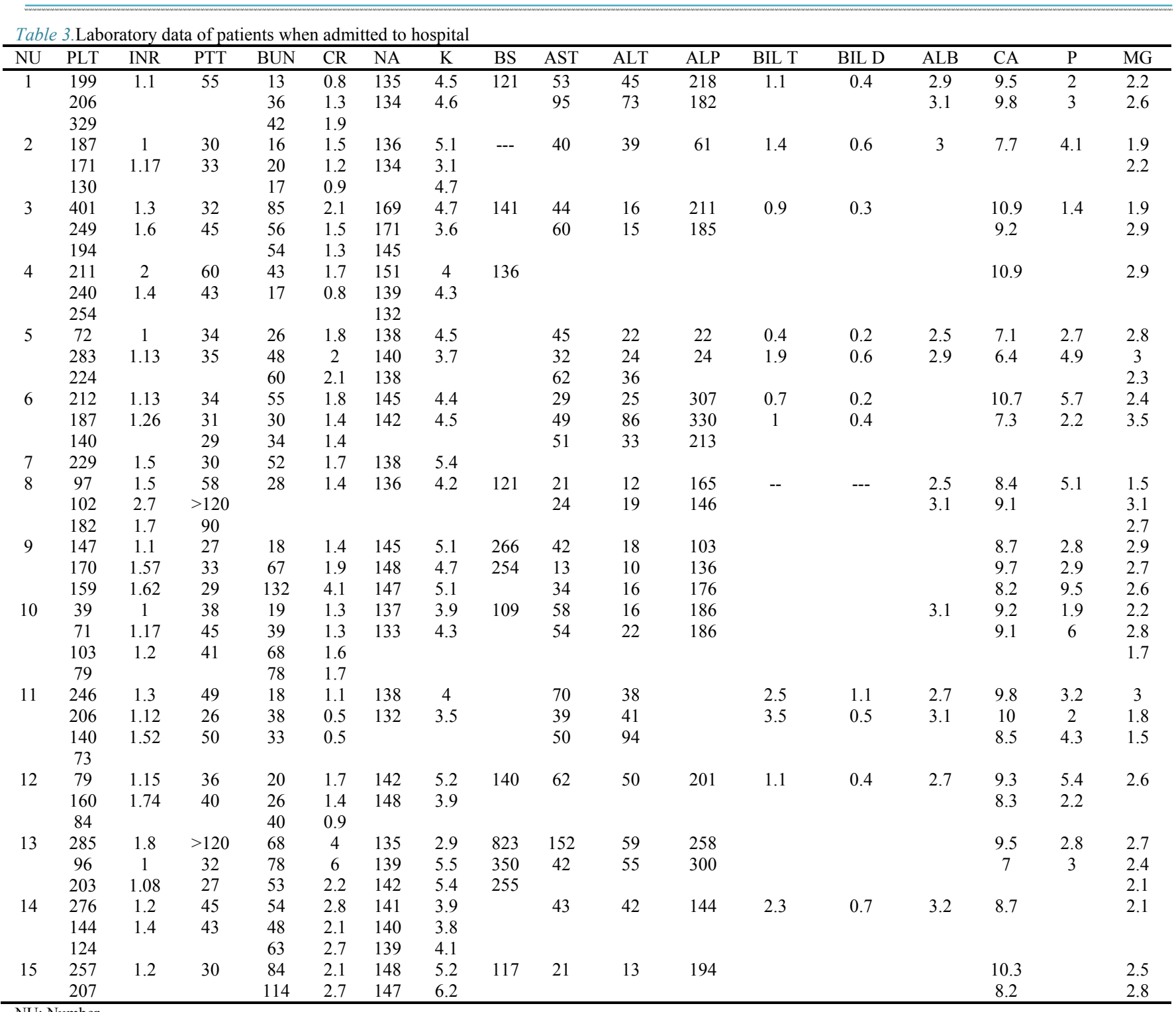

NU: Number
INR: international normalized ratio

PTT: Partial thromboplastin time

APT: Activated partial thromboplastin time

BUN: Blood Urea Nitrogen

CR: Creatinine

NA: Sodium

BS: Blood sugar

AST: Aspartate Aminotransferase

ALT : Alanine Aminotransferase

ALP: Alkaline Phosphatas

BIL: Bilirubin

ALB: Albumin

CA: Calcium

P: Phosphorus

MG: Magnesium 
S. Kooranifar, et al.

Table 4.Laboratory data of patients when admitted to hospital

\begin{tabular}{|c|c|c|c|c|c|c|c|c|c|c|c|c|c|c|}
\hline $\mathrm{NU}$ & $\mathrm{LDH}$ & $\mathrm{CPK}$ & ESR & CRP & IL6 & $\mathrm{PH}$ & $\mathrm{PCO} 2$ & $\mathrm{HCO} 3$ & $\begin{array}{c}\text { COVID } \\
\text { IGM }\end{array}$ & $\begin{array}{c}\text { COVID } \\
\text { IGG }\end{array}$ & PROCAL & $\begin{array}{l}\text { PRO } \\
\text { BNP } \\
\end{array}$ & FERR & $\mathrm{B} / \mathrm{C}$ \\
\hline \multirow[t]{2}{*}{1} & & & & & & 7.43 & 45 & 22 & & & & & & \\
\hline & & & & & & 7.32 & 50 & 26.4 & & & & & & \\
\hline \multirow[t]{3}{*}{2} & 1282 & & 81 & 48 & & 7.37 & 43 & 25 & & & & & & \\
\hline & 465 & & 74 & & & 7.44 & 40 & 27.4 & & & & & & \\
\hline & 542 & & & & & 7.45 & 50 & 35.2 & & & & & & \\
\hline \multirow[t]{3}{*}{3} & 1448 & 1005 & & & & 7.39 & 51 & 31 & & & & & & \\
\hline & 914 & & & & & 7.44 & 38 & 26 & & & & & & \\
\hline & & & & & & 7.34 & 57 & 31.6 & & & & & & \\
\hline \multirow[t]{3}{*}{4} & 46 & 38 & & & 1.5 & 7.52 & 30.3 & 25 & & & & & & \\
\hline & 509 & 386 & & & & 7.49 & 29 & 22.4 & & & & & & \\
\hline & 834 & 67 & & & & 7.50 & 32 & 25 & & & & & & \\
\hline \multirow[t]{3}{*}{5} & 1029 & 245 & 11 & 21 & 4.8 & 7.42 & 44 & 23 & NEG & NEG & 0.2 & & & NEG \\
\hline & 1780 & 314 & 28 & & & 7.38 & 47 & 22.2 & & & & & & \\
\hline & 1582 & 392 & & & & 7.46 & 42 & 24 & & & & & & \\
\hline \multirow[t]{2}{*}{6} & 458 & & & & 8.7 & 7.21 & 76 & 29.5 & & & 0.64 & & & KELEBSIELLA \\
\hline & 494 & & & & & 7.43 & 55.6 & 37.5 & & & 1.30 & & & \\
\hline \multirow[t]{2}{*}{7} & & 112 & & & 1.99 & 7.52 & 43 & 21 & + & NEG & & & & \\
\hline & & & & & & 7.43 & 50 & 23 & & & & & & \\
\hline \multirow[t]{4}{*}{8} & 675 & 112 & & & 18.7 & 7.36 & 45 & 26 & + & NEG & & & & \\
\hline & 630 & & & & & 7.56 & 21.5 & 19.6 & & & & & & \\
\hline & 437 & & & & & 7.50 & 32.9 & 26.4 & & & & & & \\
\hline & & & & & & 7.47 & 30.8 & 22.5 & & & & & & \\
\hline \multirow[t]{3}{*}{9} & 467 & & 23 & 48 & & 7.33 & 59.5 & 31.7 & & & & 40.4 & & \\
\hline & 461 & & & & & 7.5 & 26.7 & 21.2 & & & & & & \\
\hline & & & & & & 7.35 & 32.5 & 17.7 & & & & & & \\
\hline \multirow[t]{3}{*}{10} & & 754 & & 48 & 65 & 7.43 & 36.5 & 24.5 & & & & & & \\
\hline & & & & & 57 & 7.42 & 20.5 & 23 & & & & & & \\
\hline & & & & & 84 & 7.28 & 44.3 & 21.6 & & & & & & \\
\hline \multirow[t]{3}{*}{11} & & & 77 & 48 & 91 & 7.49 & 35.6 & 27.3 & & & & & & ACINTOBACTER \\
\hline & & & & & 54 & 7.45 & 43.4 & 30.3 & & & & & & \\
\hline & & & & & & 7.40 & 46.5 & 29.4 & & & & & & \\
\hline 12 & 590 & & & & 10 & 7.45 & 43.1 & 30 & & & 0.1 & 20.6 & & \\
\hline \multirow[t]{2}{*}{13} & & & 62 & & & 7.42 & 35.2 & 24.2 & & & 2.56 & & & NEG \\
\hline & & & & & & 7.38 & 40.2 & 22 & & & & & & \\
\hline \multirow[t]{2}{*}{14} & 592 & & 8 & 48 & & 7.39 & 51.7 & 31.2 & & & & & & \\
\hline & 416 & & & & & 7.36 & 52.8 & 30.1 & & & & & & \\
\hline \multirow[t]{2}{*}{15} & & 57 & & & & 7.41 & 38.9 & 25.1 & & & & & & \\
\hline & & & & & & 7.26 & 43 & 19.4 & & & & & & \\
\hline NU: & mber & & & & & & & & & & & & & \\
\hline & ibrinoger & & & & & & & & & & & & & \\
\hline Fer: & erritin & & & & & & & & & & & & & \\
\hline LDH & Lactate D & hydrog & lase & & & & & & & & & & & \\
\hline CPK & Creatine & hosphok & ase $(\mathrm{C}$ & atine $\mathrm{K}$ & ase) & & & & & & & & & \\
\hline ESR: & Erythrocy & Sedim & tation & & & & & & & & & & & \\
\hline CPR & C-Reacti & Protein & & & & & & & & & & & & \\
\hline IL6: & terleukin & 6 (IL-6) & & & & & & & & & & & & \\
\hline $\mathrm{PCO}$ & Partial $p$ & essure o & carbon & oxide & & & & & & & & & & \\
\hline IGM & Immunog & obulin & & & & & & & & & & & & \\
\hline PRO & AL :Proc & Icitonin & & & & & & & & & & & & \\
\hline Brain & natriureti & eptide & NP) & & & & & & & & & & & \\
\hline
\end{tabular}


Histopathologic evaluation of lung necropsies of 15 Iranian COVID patients

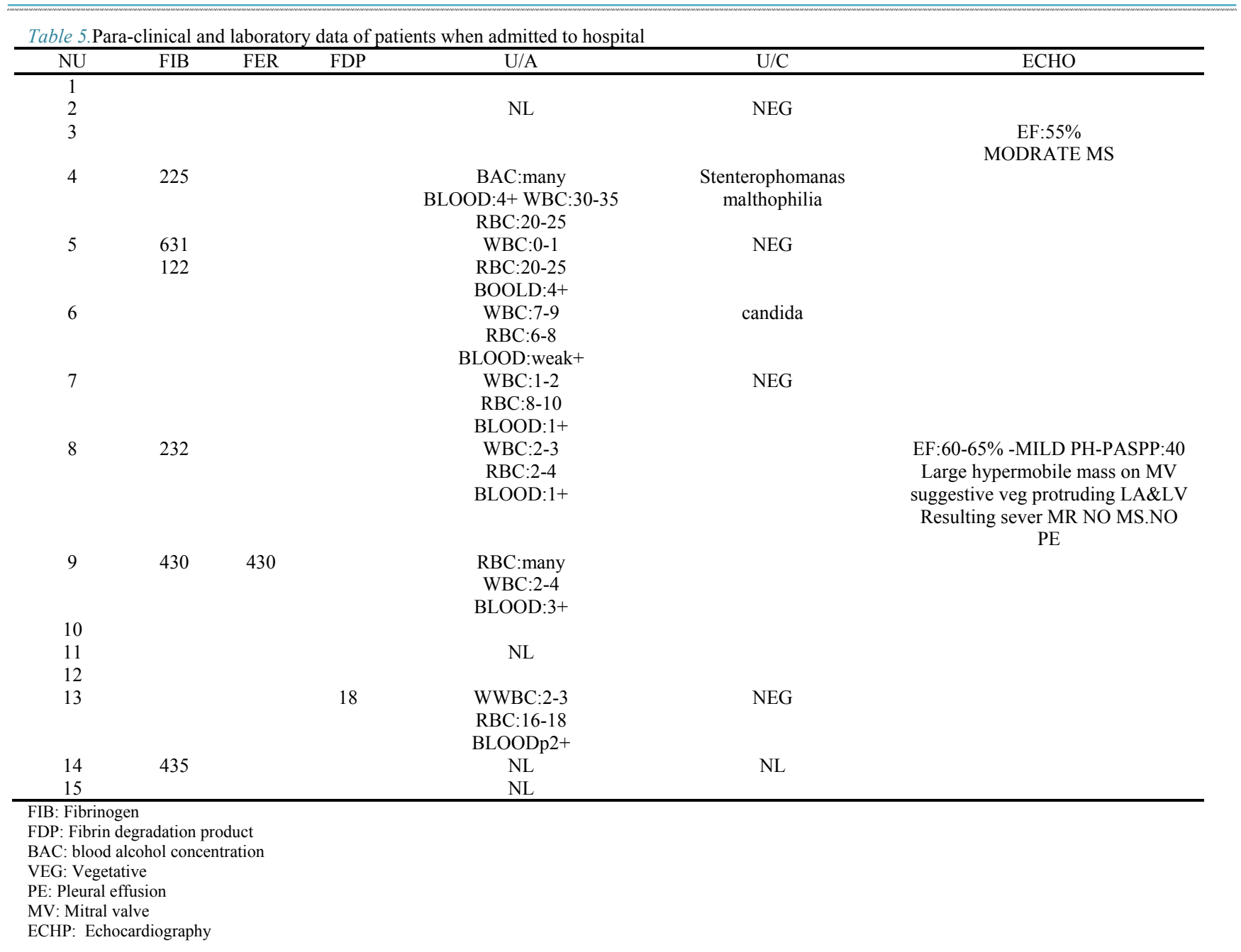




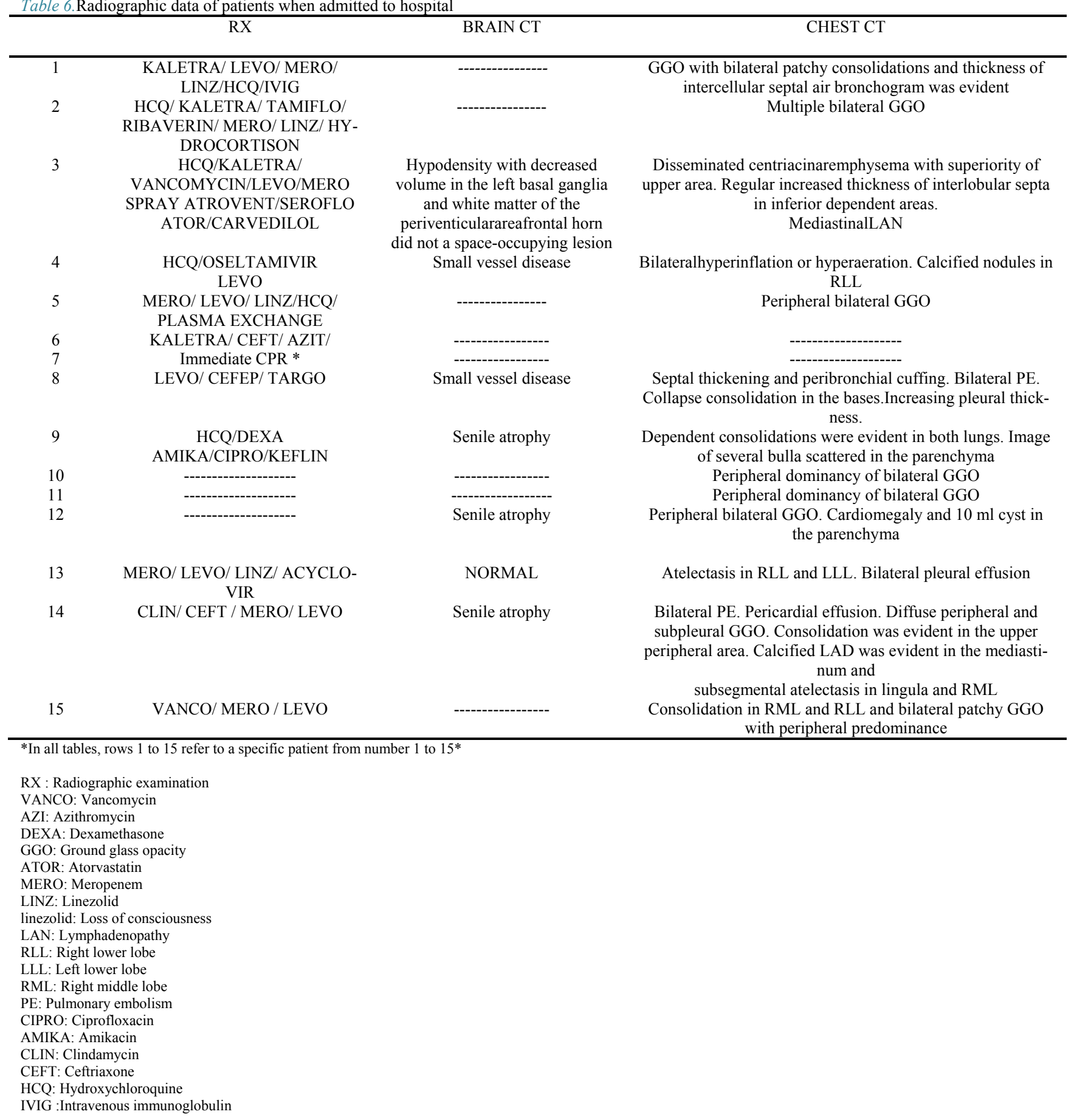

